\title{
The management of hyponatremia in cancer patients: a practical view in Spain
}

\author{
Gloria Marquina1, Emilia Gomez-Hoyos², Isabelle Runkle ${ }^{3}$ \\ 'Department of Medical Oncology, Hospital Clínico San Carlos, Madrid 28040, Spain. \\ 2Department of Endocrinology and Nutrition, Hospital Clínico Universitario de Valladolid, Valladolid 47003, Spain. \\ ${ }^{3}$ Department of Endocrinology and Nutrition, Hospital Clínico San Carlos, Madrid 28040, Spain.
}

Correspondence to: Dr. Gloria Marquina, Department of Medical Oncology, Hospital Clínico San Carlos, Madrid 28040, Spain. E-mail:gloriamarquina@gmail.com

\begin{abstract}
How to cite this article: Marquina G, Gomez-Hoyos E, Runkle I. The management of hyponatremia in cancer patients: a practical view in Spain. J Cancer Metastasis Treat2020;6:6. http://dx.doi.org/10.20517/2394-4722.2019.39
\end{abstract}

Received: 13 Oct 2019 First Decision: 6 Jan 2020 Revised: 28 Jan 2020 Accepted: 18 Feb 2020 Published: 11 Mar 2020

Science Editor: William P. Schiemann Copy Editor: Jing-Wen Zhang Production Editor: Jing Yu

\begin{abstract}
Hyponatremia is a common disorder among cancer patients and is associated with a poor prognosis in several malignancies. It is classified by volemic status into hypovolemic, euvolemic, and hypervolemic hyponatremia. Clinical history, physical examination, and blood and urine tests are important for a correct classification and diagnosis of hyponatremia, to assure correct management. Treatment of hyponatremia in cancer patients depends on the etiology of hyponatremia, as well as on the chosen therapy for the tumor. Supportive care is also a factor to be taken into account.
\end{abstract}

Keywords: Hyponatremia, sodium, cancer, syndrome of inappropriate antidiuretic hormone secretion, antidiuretic hormone, supportive care

\section{INTRODUCTION}

Hyponatremia is the most frequent electrolyte disorder found in cancer patients ${ }^{[1]}$. It is defined as a serum sodium level ( $\mathrm{SNa}$ ) of less than $135 \mathrm{mmol} / \mathrm{L}$. Hyponatremia is generally classified into mild $(130-135 \mathrm{mmol} / \mathrm{L})$, moderate $(120-129 \mathrm{mmol} / \mathrm{L})$, and severe $(<120 \mathrm{mmol} / \mathrm{L})$ according to the $\mathrm{SNa}$, and is usually correlated with its symptoms ${ }^{[2]}$, However, the velocity of descent should also be taken into account, as severe, acute hyponatremia is also defined as a drop in sodium levels of more than $10 \mathrm{mmol} / \mathrm{L}$ in $48 \mathrm{~h}$. The precise prevalence of hyponatremia in patients with cancer has yet to be determined. The

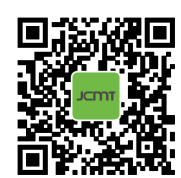


Table 1. Physical examination approach to classify hyponatremia regarding volume status ${ }^{[18]}$

\begin{tabular}{ll}
\hline Physical examination & \\
\hline $\begin{array}{l}\text { Orthostatism } \\
\text { Manual ocular pressure } \\
\text { Internal jugular venous } \\
\text { pressure }\end{array}$ & $\begin{array}{l}\text { Orthostatism can often be found in hypovolemia } \\
\text { Inspection of internal jugular vein. The maximum height of the pulse of this vein reveals the pressure in the } \\
\text { right cardiac atrium: } \\
\text { A maximum pulse height below the angle of the sternum in a reclining patient indicates hypovolemia; } \\
\text { A height between } 1 \text { and } 3 \mathrm{~cm} \text { above the sternal angle indicates euvolemia or hypovolemia with cava vein } \\
\text { thrombosis or severe pulmonary hypertension; }\end{array}$ \\
& $\begin{array}{l}\text { A height over } 4 \mathrm{~cm} \text { indicates elevated right atrial pressure, as is found in congestive heart failure } \\
\text { Hypervolemic status usually presents with an increased third space such as edema or ascites }\end{array}$ \\
\hline $\begin{array}{l}\text { Edema/increase of } \\
\text { liquids in a "third space" }\end{array}$ & \\
\hline
\end{tabular}

frequency of hyponatremia varies depending on the type of tumor, clinical scenario, and the threshold used for definition of hyponatremia. However, up to $47 \%$ of patients in the oncology ward $^{[3]}$ have been found to present hyponatremia. Furthermore, hyponatremia can precede the diagnosis of malignancy, with incidences between $1 \%$ and $40 \%{ }^{[4]}$.

Historically, hyponatremia has been more frequently associated with small cell lung cancer than with other tumors ${ }^{[5]}$. However, other publications establish that this hydro-electrolytic alteration can be detected in any cancer patient ${ }^{[3,6]}$. Direct cancer-induced hyponatremia could be due to ectopic arginine vasopressin secretion, inducing the Syndrome of Inappropriate Antidiuretic Hormone Secretion (SIADH). Furthermore, there is emerging evidence for expression of sodium-transporting proteins in cancer ${ }^{[7]}$.

Hyponatremia can also be attributed to other etiologies that are not related per se to the cancer. What is more, hyponatremia can be induced by cancer-related complications, as well as the anti-cancer treatment itself $^{[8]}$ or the side effects of cancer therapy. These include diarrhea, nausea, vomiting, pain, nephrotoxicity, adrenal insufficiency (due to adrenal metastases), etc. ${ }^{[5]}$.

Hyponatremia can be a potential negative prognostic factor in patients diagnosed with solid tumors or hematological malignancies such as lung cancer, breast cancer, lymphoma, and colorectal cancer ${ }^{[5]}$. In cirrhosis, hyponatremia is associated with a higher morbidity and mortality. Decompensated cirrhosis in liver cancer patients represents an additional complicating factor ${ }^{[9]}$.

Hyponatremia detected in in-hospital cancer patients is associated with a longer hospital length of stay and an increased risk of mortality ${ }^{[4,6,10-13]}$.

The impact of correction of hyponatremia on patient survival has yet to be ascertained. In some patient series, the correction of hyponatremia correlates with an improvement in quality of life and an improved $\operatorname{prognosis}^{[4,14]}$.

\section{THE DIAGNOSTIC APPROACH TO HYPONATREMIA IN CANCER PATIENTS}

The diagnostic approach in cancer patients should be the same as for any patient with hyponatremia ${ }^{[2,15]}$. The physical examination is fundamental, since it can establish the volume status of the patient [Table 1]; the clinical history, blood and urine tests are also necessary [Table 2] to determine the etiology [Table 3] $]^{[16,17]}$.

The initial step in laboratory evaluation of hyponatremia, after detecting a sodium level below $135 \mathrm{mmol} / \mathrm{L}$, is to assure that hyponatremia is truly present. High glycemic levels, or mannitol infusion can induce translocational hyponatremia. In fact, total blood or serum sodium levels must always be corrected in patients with hyperglycemia. In patients receiving mannitol infusion, a normal plasma osmolality will rule 
Table 2. Basic blood and urine tests for the diagnosis of the cause of hyponatremia

\begin{tabular}{lll}
\hline Blood test (serum) & Urine test & Gasometer \\
\hline Protein & & \\
Glucose & & \\
Urea & Creatinine & \\
Creatinine & Osmolality & Sodium \\
Osmolality & Sodium & \\
Sodium & Potassium & \\
Potassium & Chlorine & \\
Chlorine & & \\
Cortisol & & \\
TSH & & \\
T4 & & \\
\hline
\end{tabular}

TSH: thyroid stimulating hormone; T4: thyroxine

Table 3. Approach to diagnosis

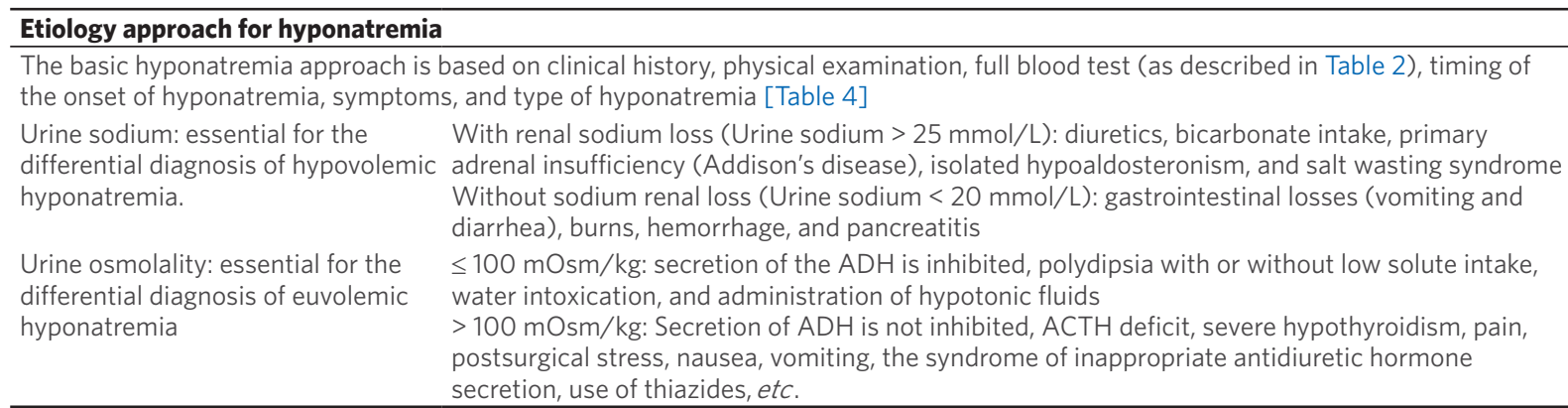

ADH: antidiuretic hormone; ACTH: adrenocorticotropic hormone

out true hyponatremia. Pseudohyponatremia, induced by high protein or lipid levels, can be excluded by the determination of total blood sodium by gasometer.

The best and most direct way to ascertain whether the patient presents hypovolemic or euvolemic eunatremia is by neck inspection of the highest point of the internal jugular vein pulse [Table 1$]^{[18]}$. The evolution of serum creatinine together with $\mathrm{SNa}$ is also a good parameter. Serum creatinine usually increases when natremia drops in the hypovolemic patient and usually decreases along with hyponatremia in the euvolemic patient ${ }^{[14]}$.

An appropriate intervention depends on determining the timing of hyponatremia onset, the severity of the neurological symptoms, and the volemic classification [Table 4]. This information, together with clinical history and blood and urine tests, is the basis for determining the etiology of hyponatremia [Table 3].

Note that a single patient could experience different volemic episodes (e.g., hypovolemic after having been euvolemic) sequentially ${ }^{[19]}$. That is why clinical examination remains necessary to assure correct management of hyponatremia at any given point of time, and reevaluation of patients is essential.

Hyponatremia in oncology patients is often considered primarily euvolemic, secondary to SIADH ${ }^{[20]}$. However, some studies have found that hypovolemic or hypervolemic hyponatremia is more prevalent in hospitalized cancer patients ${ }^{[3,6]}$.

The clinician should remember that the diagnosis of SIADH is always a diagnosis of exclusion ${ }^{[21]}$, in a euvolemic patient with a urine osmolality higher than $100 \mathrm{mOSm} / \mathrm{kg}$, in the absence of pain, nausea, diuretics, adrenocorticotropic hormone $(\mathrm{ACTH})$ deficit, diuretic use, or severe hypothyroidism. ACTH 
Table 4. Hyponatremia clinical approach

\begin{tabular}{|c|c|c|}
\hline \multicolumn{3}{|l|}{ Hyponatremia approach } \\
\hline $\begin{array}{l}\text { Timing of the onset of } \\
\text { hyponatremia }\end{array}$ & \multicolumn{2}{|c|}{$\begin{array}{l}\text { Acute: onset less than } 48 \mathrm{~h} \text { earlier } \\
\text { Chronic: onset more than } 48 \mathrm{~h} \text { earlier } \\
{ }^{*} \text { Hyponatremia should be considered chronic when timing of onset is unknown }\end{array}$} \\
\hline \multirow[t]{3}{*}{ Neurological symptoms } & Mild & $\begin{array}{l}\text { Impaired capacity for concentration } \\
\text { Cognitive deficit } \\
\text { Gait disturbances and falls } \\
\text { Memory loss } \\
\text { Anorexia }\end{array}$ \\
\hline & Moderate & $\begin{array}{l}\text { Cramps } \\
\text { Drowsiness } \\
\text { Headache } \\
\text { Nausea } \\
\text { Vomiting } \\
\text { Asthenia } \\
\text { Impaired gait and falls } \\
\text { Confusion }\end{array}$ \\
\hline & Severe & $\begin{array}{l}\text { Lethargy } \\
\text { Stupor } \\
\text { Seizures } \\
\text { Coma } \\
\text { Respiratory distress } \\
\text { Sudden death }\end{array}$ \\
\hline $\begin{array}{l}\text { Type of hyponatremia: } \\
\text { volemic classification }\end{array}$ & $\begin{array}{l}\text { Hypovolemic } \\
\text { Euvolemic } \\
\text { Hypervolemic }\end{array}$ & \\
\hline
\end{tabular}

deficit is often overlooked, and all patients who are not receiving pharmacological steroid doses should have cortisolemia determined.

\section{TREATMENT OF HYPONATREMIA IN CANCER PATIENTS}

Hyponatremia should be treated to both correct clinical symptoms and permit adequate oncological and nutritional therapy. Furthermore, correction of hyponatremia could potentially influence the cancer patient's quality of life.

\section{A patient who is a candidate for chemotherapy}

\section{Severe hyponatremia $(\mathrm{Na}<120 \mathrm{mmol} / \mathrm{L})$}

The management of cancer patients is exactly the same as is the case for a non-oncological patient. Hypertonic saline solution ( $3 \%$ sodium chloride) should be administered in i.v. infusion or in bolus therapy, regardless of the type or etiology of hyponatremia. The rate of correction will vary if hyponatremia is chronic or acute. In acute hyponatremia $(<48 \mathrm{~h})$, there are no established limits for correction of hyponatremia. In chronic hyponatremia $(>48 \mathrm{~h}$ ) or when the timing of the onset of hyponatremia is unknown, the goal of correction in the first $24 \mathrm{~h}$ should be a SNa rise of 4-6 $\mathrm{mmol} / \mathrm{L}$, reached during the first $6 \mathrm{~h}$ of treatment, to reduce cerebral edema [Figure 1].

Additional treatments for hyponatremia must be avoided during the first $24 \mathrm{~h}$ of correction, except for associated furosemide in patients with heart failure or the addition of potassium chloride in patients with initial hypokalemia ${ }^{[2,14]}[\text { Table } 5]^{[22]}$.

Hypercorrection of SNa should be avoided in patients with chronic hyponatremia ( $>48 \mathrm{~h}$ from onset) or when the timing of the onset of hyponatremia is unknown. Patients presenting risk factors for the Osmotic Demyelination Syndrome (ODS) (hypokalemia, malnutrition, liver failure, and alcoholism) should not present 24 -h SNa rises above $8 \mathrm{mmol} / \mathrm{L}$ during the first or second $24 \mathrm{~h}$ of therapy. Therefore, following Hypertonic saline therapy, SNa should be monitored every 6-8 h. If SNa re-descends, hypertonic saline can 
Table 5. The 24- and 48-h goals for correction of chronic hyponatremia (adapted from ${ }^{[22]}$ )

\begin{tabular}{|c|c|c|c|c|c|}
\hline ODS risk & $\begin{array}{l}\text { Minimum } 24 \text { h SNa } \\
\text { rise }(\mathrm{mmol} / \mathrm{L})\end{array}$ & 24 h Goal (mmol/L) & $\begin{array}{l}\text { Maximum } 24 \mathrm{~h} \mathrm{SNa} \\
\text { rise }(\mathrm{mmol} / \mathrm{L})\end{array}$ & 48 h Goal (mmol/L) & $\begin{array}{c}\text { Maximum } 48 \mathrm{~h} \mathrm{SNa} \\
\text { rise }(\mathrm{mmol} / \mathrm{L})\end{array}$ \\
\hline Low & $4-8$ & $6-8$ & $10-12$ & $6-8$ & 18 \\
\hline High & $4-6$ & 6 & 8 & $4-6$ & $8 /$ day \\
\hline
\end{tabular}

ODS: osmotic demyelination syndrome; SNa: serum sodium

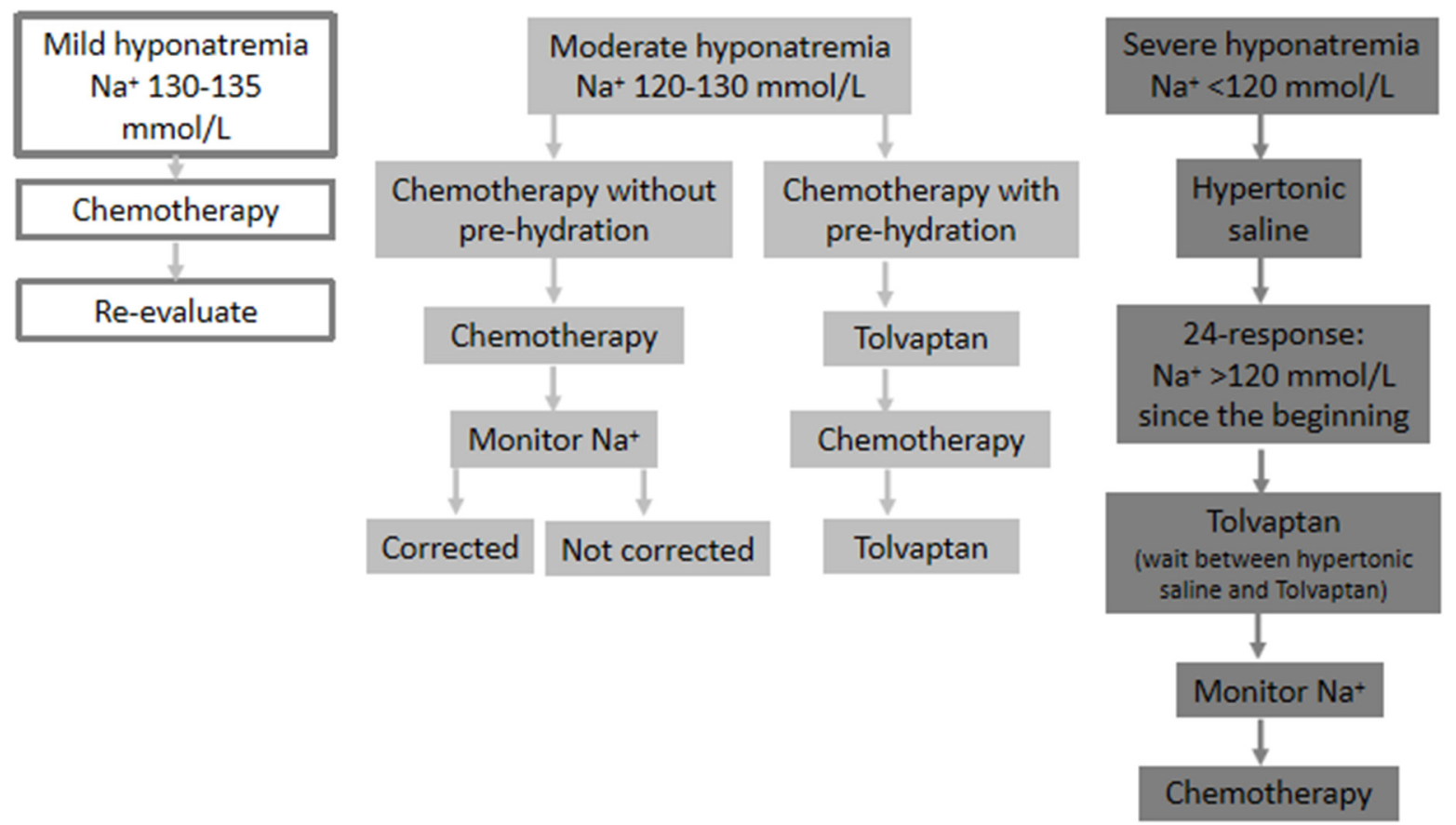

Figure 1. When the patient is a candidate for chemotherapy (modified from Escobar et al. ${ }^{[29]}$ )

be administered anew. If SNa levels have reached the desired goal hours before $24 \mathrm{~h}$ have elapsed since the start of treatment, desmopressin (DDAVP) can be associated at doses of 1-2 $\mu \mathrm{g}$ every 6-8 $\mathrm{h}$ until the $24 \mathrm{~h}$ have elapsed, to prevent SNa levels from continuing to increase. Diuresis should be monitored and DDAVP administered in the case of polyuria.

A marked exception to the use of hypertonic saline is the suspicion of an adrenal crisis. In this case, established protocols for treatment should be applied, with i.v. hypertonic saline only used if the patient's $\mathrm{SNa}$ fails to rise adequately $\mathrm{y}^{[2,19]}$.

\section{Mild/moderate hypovolemic hyponatremia}

Management will depend on the cause of hyponatremia. Diarrhea and vomiting are frequent side effects of chemotherapy. Antiemetics and adequate hydration and salt intake can be enough to correct non-severe hypovolemic hyponatremia, although i.v. isotonic saline can be required.

If it is mild hyponatremia, the patient can proceed with chemotherapy and control serum sodium levels in outpatient clinic.

\section{Mild/moderate hypervolemic or euvolemic hyponatremia}

In patients with a diagnosis of SIADH, fluid restriction can be attempted if patients are not candidates for surgery, hyperhydration, or nutritional supplements or support. Furthermore, patients at nutritional risk could limit protein intake when reducing fluids, as the latter are usually needed to eat solids. Fluid 


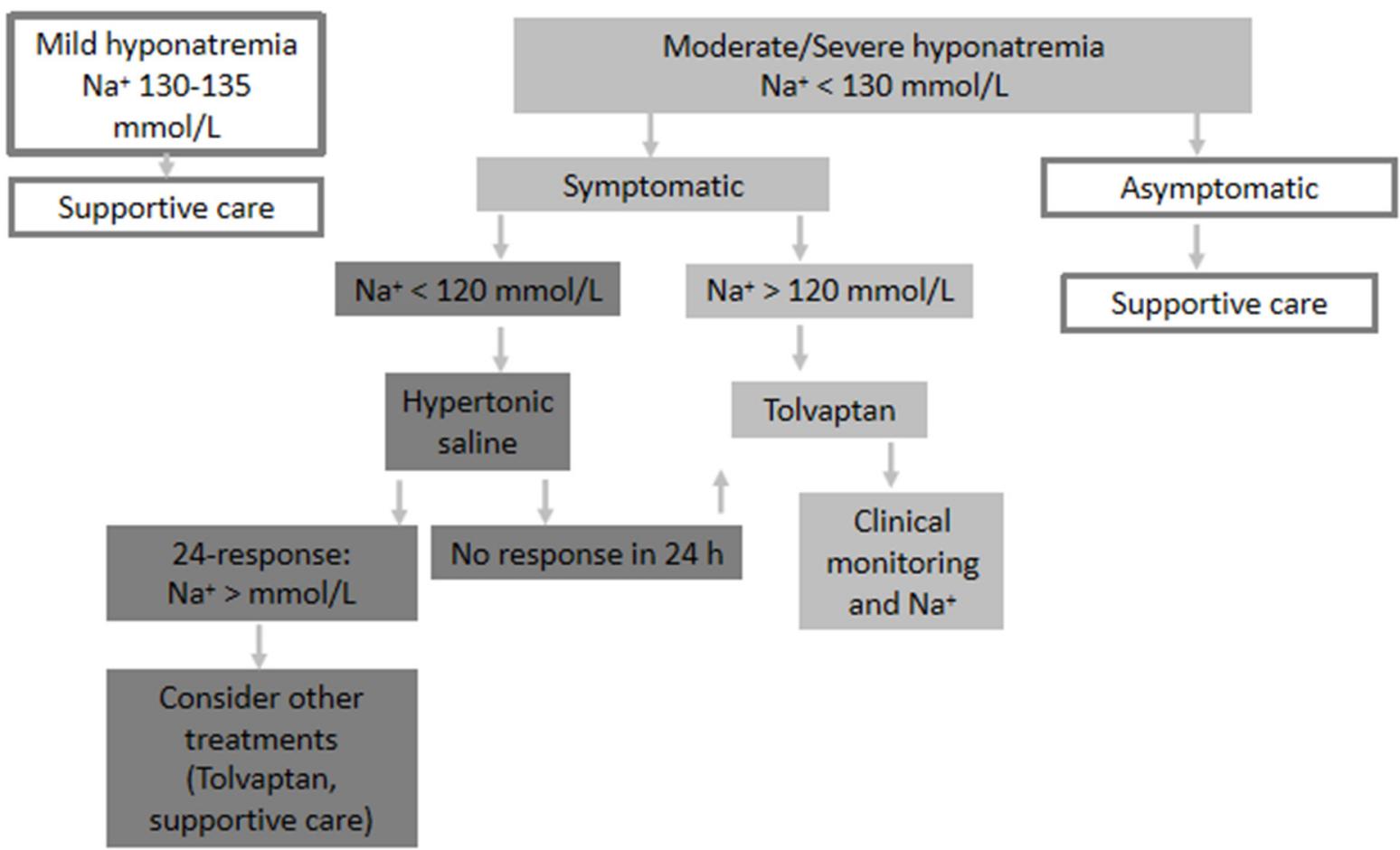

Figure 2. When the patient is not a candidate for chemotherapy (modified from Escobar et al. ${ }^{[29]}$ )

restriction refers to all administered liquids, including i.v. medication and semisolids administered in the diet.

Fluid restriction should not be attempted if the patient's biochemistry indicates their kidneys are unable to eliminate free water. To ascertain response, the Furst formula can be applied.

The first approach is fluid restriction and increased salt intake in diet, applying the Furst formula ${ }^{[23]}$ :

(Urine sodium + Urine $\mathrm{K}$ )/Serum sodium

The result of this formula will predict whether fluid restriction will be effective for the treatment of hypervolemic or euvolemic hyponatremia, and the threshold of the liquid restriction: $(1)<0.5$ : fluid restriction of < $1000 \mathrm{cc} /$ day; (2) $0.5-1$ : fluid restriction of < $500 \mathrm{cc} /$ day; $(3)>1$ : fluid restriction ineffective.

In cancer patients with a high prevalence of and risk for malnutrition and the frequent need for dilution of chemotherapy, fluid restriction is often not viable ${ }^{[14,19]}$.

Evidence in favor of the use of fluid restriction in patients with hypervolemic hyponatremia is scant ${ }^{[24]}$. However, its use has been incorporated into therapeutic algorithms of congestive heart failure. If there is no response to fluid restriction, Tolvaptan could be considered ${ }^{[25]}$.

\section{Patients who are not candidates for chemotherapy}

Supportive treatment and treatment of hyponatremia should be prioritized according to the severity of the symptoms, rather than the level of hyponatremia per se [Figure 2].

\section{Hyponatremia due to SIADH in cancer patients}

Tolvaptan is approved for the treatment of SIADH-induced hyponatremia in adult patients ${ }^{[26-28]}$. 
The Spanish Medical Oncology Society (SEOM) has developed an algorithm which could be useful for the management of hyponatremia secondary to SIADH in cancer patients ${ }^{[29]}$ based on the prior algorithm developed in Spain for hyponatremia patients ${ }^{[30]}$.

According to the SEOM algorithm, management will depend on the two scenarios mentioned above: the patient is a candidate $v s$. a non-candidate for chemotherapy.

When the patient is a candidate for chemotherapy [Figure 1]

(1) Mild hyponatremia (130-135 mmol/L): proceed with chemotherapy. Re-evaluate during the next cycle. Note that there are discrepancies in this point, as Tolvaptan would prevent the exacerbation of hyponatremia and the development of severe hyponatremia following the first cycle of chemotherapy ${ }^{[19]}$;

(2) Moderate hyponatremia (120-130 mmol/L): consider Tolvaptan if chemotherapy requires pre-hydration, hyponatremia is progressively worsening, or hyponatremia is symptomatic. As mentioned above for mild hyponatremia, Tolvaptan could prevent worsening hyponatremia;

(3) Severe hyponatremia $(<120 \mathrm{mmol} / \mathrm{L})$ : use the same as treatment as for severe hyponatremia. Once 24$48 \mathrm{~h}$ have elapsed following therapy with hypertonic saline solution, Tolvaptan could be started.

When SIADH-induced hyponatremia is caused by the anti-cancer treatment itself (for example, vincristine ${ }^{[8]}$, a modification of cancer therapy should be considered. When a change in medication is not feasible, SIADH in these cases should be treated with Tolvaptan.

When the patient is not a candidate for chemotherapy [Figure 2]

As mentioned above, supportive treatment and treatment of hyponatremia should be prioritized according to the severity of the symptoms, rather than the level of hyponatremia per se:

(1) Mild hyponatremia (130-135 mmol/L): focus on supportive care management;

(2) Very symptomatic moderate/severe hyponatremia (< $130 \mathrm{mmol} / \mathrm{L})$ : consider Tolvaptan. If $<120 \mathrm{mmol} / \mathrm{L}$, treat the acute phase with hypertonic sodium solution and, once stabilized, consider Tolvaptan;

(3) Mild symptomatic moderate/severe hyponatremia $(<130 \mathrm{mmol} / \mathrm{L})$ : focus on supportive care management.

\section{DECLARATIONS}

\section{Authors' contributions}

Wrote and reviewed the manuscript: Marquina G, Gomez-Hoyos E, Runkle I

\section{Availability of data and materials}

Not applicable.

\section{Financial support and sponsorship}

None.

\section{Conflicts of interest}

All authors declared that there are no conflicts of interest.

\section{Ethical approval and consent to participate}

Not applicable.

\section{Consent for publication}

Not applicable. 


\section{Copyright}

(c) The Author(s) 2020.

\section{REFERENCES}

1. De las Peñas R, Escobar Y, Henao F, Blasco A, Rodríguez CA. SEOM guidelines on hydroelectrolytic disorders. Clin Transl Oncol 2014;16:1051-9.

2. Verbalis JG, Goldsmith SR, Greenberg A, Korzelius C, Schrier RW, et al. Diagnosis, evaluation, and treatment of hyponatremia: expert panel recommendations. Am J Med 2013;126:S1-42.

3. Marquina G, Runkle I, Manzano A, Granja M, Aguado C, et al. Incidence, classification and diagnosis of hypo- natremia in patients admitted to the oncology ward. J Clin Oncol 2015;33:e20656.

4. Castillo JJ, Glezerman IG, Boklage SH, Chiodo J, Tidwell BA, et al. The occurrence of hyponatremia and its importance as a prognostic factor in a cross-section of cancer patients. BMC Cancer 2016;16:564.

5. Berardi R, Rinaldi S, Caramanti M, Grohè C, Santoni M, et al. Hyponatremia in cancer patients: time for a new approach. Crit Rev Oncol Hematol 2016;102:15-25.

6. Zylberman M, Couselo FAD. Incidencia y mortalidad de la hiponatremia en pacientes con cáncer. Diálisis Traspl 2010;10.

7. Djamgoz MBA, Fraser SP, Brackenbury WJ. In vivo evidence for voltage-gated sodium channel expression in carcinomas and potentiation of metastasis. Cancers 2019;11:1675.

8. Berardi R, Santoni M, Rinaldi S, Nunzi E, Smerilli A, et al. Risk of hyponatraemia in cancer patients treated with targeted therapies: a systematic review and meta-analysis of clinical trials. PLoS One 2016;11:e0152079.

9. Bengus A, Babiuc RD. Hyponatremia - predictor of adverse prognosis in cirrhosis. J Med Life 2012;5:176-8.

10. Doshi SM, Shah P, Lei X, Lahoti A, Salahudeen AK. Hyponatremia in hospitalized cancer patients and its impact on clinical outcomes. Am J Kidney Dis 2012;59:222-8.

11. Abu Zeinah GF, Al-Kindi SG, Hassan AA, Allam A. Hyponatraemia in cancer: association with type of cancer and mortality: hyponatraemia and cancer mortality. Eur J Cancer Care (Engl) 2015;24:224-31.

12. Castillo JJ, Vincent M, Justice E. Diagnosis and management of hyponatremia in cancer patients. Oncologist 2012;17:756-65.

13. Hiponatremia en oncología. Nefrología [Internet]. 2011. Available from: http://doi.org/10.3265/NefrologiaSuplementoExtraordinario. pre2011.Sep.11149

14. Peri A. Prognostic and predictive role of hyponatremia in cancer patients. J Cancer Metastasis Treat 2019;5:40.

15. Ball SG, Iqbal Z. Diagnosis and treatment of hyponatraemia. Best Pract Res Clin Endocrinol Metab 2016;30:161-73.

16. Aylwin S, Burst V, Peri A, Runkle I, Thatcher N. 'Dos and don'ts' in the management of hyponatremia. Curr Med Res Opin 2015;31:1755-61.

17. Tzoulis P, Runkle-De la Vega I. The diagnostic approach to the patient with hyponatremia: are the correct investigations being done? In: Peri A, Thompson CJ, Verbalis JG, editors. Frontiers of Hormone Research. S. Karger AG; 2019. pp. 190-9.

18. Ploutarchos T, Runkle I. Hyponatraemia in clinical practice: are we investigating and treating appropriately? In Disorders of fluid and electrolyte metabolism. FOCUS: Hyponatremia. Hormone Research 2019. Frontiers of Hormone Research 2019. vol 52: 190-199.

19. Runkle I, Chafer J. El diagnóstico diferencial de la hiponatremia. In: Gomez-Hoyos E, Runkle I. Manual Enigmas de la Hiponatremia. Barcelona: Permanyer; 2018. pp. 11-13.

20. Petereit C, Zaba O, Teber I, Lüders H, Grohé C. A rapid and efficient way to manage hyponatremia in patients with SIADH and small cell lung cancer: treatment with tolvaptan. BMC Pulm Med 2013;13:55.

21. Onitilo AA, Kio E, Doi SAR. Tumor-related hyponatremia. Clin Med Res 2007;5:228-37

22. Runkle I, Gomez-Hoyos E, Cuesta-Hernández M, Chafer-Vilaplana J, de Miguel P. Hyponatraemia in older patients: a clinical and practical approach. Rev Clin Gerontol 2015;25:31-52.

23. Furst H, Hallows KR, Post J, Chen S, Kotzker W, et al. The urine/plasma electrolyte ratio: a predictive guide to water restriction. Am J Med Sci 2000;319:240-4.

24. Johansson P, van der Wal MH, Strömberg A, Waldréus N, Jaarsma T. Fluid restriction in patients with heart failure: how should we think? Eur J Cardiovasc Nurs 2016;15:301-4.

25. Pose A, Almenar L, Manzano L, Gavira JJ, López Granados A, et al. Hyponatraemia and congestive heart failure refractory to diuretic treatment. Utility of tolvaptan. Rev Clin Esp 2017;217:398-404.

26. Schrier RW, Berl T, Orlandi C. Tolvaptan, a selective oral vasopressin v2-receptor antagonist, for hyponatremia. N Engl J Med 2006;355:2099-112.

27. Verbalis JG, Adler S, Schrier RW, Berl T, Zhao Q, et al. Efficacy and safety of oral tolvaptan therapy in patients with the syndrome of inappropriate antidiuretic hormone secretion. Eur J Endocrinol 2011;164:725-32.

28. Berardi R, Antonuzzo A, Blasi L, Buosi R, Lorusso V, et al. Practical issues for the management of hyponatremia in oncology. Endocrine 2018;61:158-64

29. Escobar AY, Henao CF, de las Penas Bataller R, Rodríguez CA. Algoritmo de tratamiento de la hiponatremia asociada al SIADH en el paciente oncológico. Sociedad Española de Oncología Médica 2014. Available from: http://www.seom.org/es/publicaciones/ publicacionesseom/104548-algoritmo- seomdel-manejo-de-la-hi- ponatremiaen-el-paciente-oncologico [Last accessed on 21 Feb 2020]

30. Runkle I, Villabona C, Navarro A, Pose A, Formiga F, et al. El tratamiento de la hiponatremia secundaria al síndrome de secreción inadecuada de la hormona antidiurética. Med Clin (Barc) 2013;141:507e1-10. 